\title{
The neglected perioperative population of undiagnosed diabetics - a retrospective cohort study
}

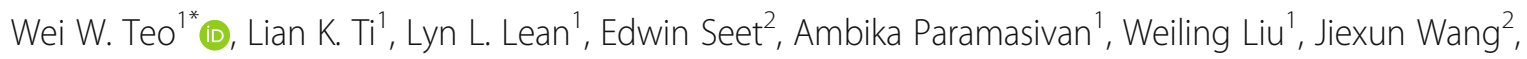
Vanessa Chua ${ }^{1}$ and Lydia Q. Liew ${ }^{1}$

\begin{abstract}
Background: Diabetes is known to increase morbidity and 30-day mortality in adults undergoing non-cardiac surgery, but longer term outcomes are less studied. This study was done to explore how undiagnosed and known diabetes affect 30-day and one-year morbidity and mortality outcomes. The secondary aim was to study the prevalence of undiagnosed diabetics in our perioperative Asian surgical population.

Methods: A retrospective cohort study of 2106 patients aged $\geq 45$ years undergoing non-cardiac surgery in a single tertiary hospital was performed. Undiagnosed diabetics were identified (HbA1c $\geq 6.5 \%$ or fasting blood glucose $\geq 126 \mathrm{mg} / \mathrm{dL}$ ) and relevant demographic, clinical and surgical data were analyzed to elicit the relationship to adverse outcomes. Univariate analysis was first performed to identify significant variables with $p$-values $\leq 0.1$, which were then analyzed using multiple logistic regression to calculate the adjusted odds ratio.

Results: The prevalence of undiagnosed diabetes was $7.4 \%$. The mean and median HbA1c of known diabetics were 7.9 and $7.5 \%$, while the mean and median HbA1c for undiagnosed diabetics were 7.2 and $6.8 \%$ respectively. $36.4 \%$ of known diabetics and $20.5 \%$ of undiagnosed diabetics respectively had a random blood glucose $>200 \mathrm{mg} / \mathrm{dL}$. Undiagnosed diabetics had a three-fold increase in 1-year mortality compared to non-diabetics (adjusted OR 3.46(1.80-6.49) $p<0.001$ ) but this relationship was not significant between known and non-diabetics. Compared to non-diabetics, known diabetics were at increased risks of new-onset atrial fibrillation (aOR 2.48(1.01-6.25) $p=0.047$ ), infection (aOR 1.49(1.07-2.07) $p=$ 0.017), 30-day readmission (aOR 1.62(1.17-2.25) $p=0.004)$ and 30-day mortality (aOR 3.11(1.16-8.56) $p=0.025)$.

Conclusions: Although undiagnosed diabetics have biochemically less severe disease compared to known diabetics at the point of testing, they are at a one-year mortality disadvantage which is not seen among known diabetics. This worrying trend highlights the importance of identifying and treating diabetes. Congruent to previous studies, known diabetics have higher morbidity and 30-day mortality compared to non-diabetics.
\end{abstract}

Keywords: Diabetes mellitus, General surgery, Morbidity, Mortality, Asian

\footnotetext{
* Correspondence: wei_wei_teo@nuhs.edu.sg

${ }^{1}$ Department of Anaesthesia, National University Health System, 5 Lower Kent Ridge Road, Singapore 119074, Singapore

Full list of author information is available at the end of the article
}

(c) The Author(s). 2020 Open Access This article is licensed under a Creative Commons Attribution 4.0 International License, which permits use, sharing, adaptation, distribution and reproduction in any medium or format, as long as you give appropriate credit to the original author(s) and the source, provide a link to the Creative Commons licence, and indicate if changes were made. The images or other third party material in this article are included in the article's Creative Commons licence, unless indicated otherwise in a credit line to the material. If material is not included in the article's Creative Commons licence and your intended use is not permitted by statutory regulation or exceeds the permitted use, you will need to obtain permission directly from the copyright holder. To view a copy of this licence, visit http://creativecommons.org/licenses/by/4.0/ The Creative Commons Public Domain Dedication waiver (http://creativecommons.org/publicdomain/zero/1.0/) applies to the data made available in this article, unless otherwise stated in a credit line to the data. 


\section{Background}

Type 2 diabetes mellitus is one of the most prevalent and morbid conditions affecting the lives of over 400 million people worldwide [1]. Its prevalence is estimated to double within 20 years in the United States alone [2]. The disease is a major cause of microvascular and macrovascular complications including blindness, renal failure, cardiovascular and cerebrovascular events, with significant impact on quality of life and life expectancy.

More than 200 million adults undergo major noncardiac surgery every year, and a significant proportion have diabetes [3]. Numerous studies have demonstrated a clear association between perioperative hyperglycemia and diabetes with increased morbidity related outcomes including higher rates of infection and longer hospital length of stay [4-8]. An observational study also demonstrated significant association between increased perioperative glucose level and mortality risk amongst patients without prior diagnosis of diabetes, but not the known diabetics [9]. However the results are to be interpreted with caution as a significant proportion of the hyperglycaemic patients included could have actually been underdiagnosed diabetics. A previous large retrospective study on a Western population had shown the prevalence of undiagnosed diabetes to be a significant $10 \%$ of the surgical population [10]. However to date, there is a paucity of studies looking into the implications on perioperative morbidity and mortality, regardless of the patient's preoperative glycemic status. Although many studies agree that diabetes increases postoperative morbidity and 30-day mortality, it has not been shown to affect 1-year mortality outcomes [4, 5, 11-13].

An epidemiological study in 2013 estimated that there are 170 million cases of undiagnosed diabetes globally while another prospective study showed a prevalence of $13.4 \%$ of undiagnosed diabetes in their intensive care unit [14]. Diagnosis of diabetes remains challenging due to the often insidious onset of symptoms, low disease awareness amongst the public and limited healthcare resources for screening. Asians have a different metabolic profile and adipose distribution that has seen a shift in the definition of obesity between Asians and Westerners. This shift could potentially be applicable to diabetes and account for differences in demographics, risk factors and disease trajectory, and could explain the increased prevalence of diabetes in Asians [15]. Furthermore, most screening criteria for diabetes are largely developed by Westerners that may not be specific to the Asian population.

This study was done primarily to explore how undiagnosed and known diabetes affect both 30-day and 1-year morbidity and mortality outcomes when compared to non-diabetics. The secondary outcome was to look at the prevalence of undiagnosed diabetics in our perioperative Asian surgical population.

\section{Methods}

Following ethics committee approval from the Institutional Review Board (National Healthcare Group Domain Specific Review Board reference: 2016/01273), a retrospective cohort study of 2300 patients aged 45 years old and above undergoing non-cardiac surgery from January 2015 to July 2015 was performed in a universityaffiliated tertiary hospital.

Patients undergoing surgery were identified through operating theatre audit records which capture $>90 \%$ of patients undergoing any form of surgery. Members of the research team used International Classification of Diseases coding and manually reviewed each patient's electronic medical records to obtain relevant information pertaining to their baseline characteristics, comorbidities and nature of surgery.

The inclusion criteria included patients 45 years old and above undergoing intermediate or high-risk noncardiac surgery, defined as surgery requiring at least $23 \mathrm{~h}$ stay in hospital. Patients undergoing multiple surgeries had only the index surgery considered, with their subsequent surgeries excluded from the analysis, resulting in a total of 2106 patient encounters analysed.

Relevant demographic, clinical and surgical data were analysed to elicit their relationship to mortality at 1 year after surgery. The presence or absence of patient comorbidities were considered positive if they were known to be present at the time of surgery as indicated by anaesthetic records. These records are routinely obtained by direct patient questioning as well as by searching electronic hospital records. Laboratory investigations were analysed if they were performed within 6 months prior to surgery with no change in patient's medical status in between. If there were more than one of the same investigation performed in the same patient, the one done closest to the time of surgery was used for analysis. All perioperative factors studied are shown in Table 1.

The adverse outcomes investigated were mortality at 30 days, mortality at 1 year, new onset atrial fibrillation, development of any infection including urinary tract, lung, line and surgical site, as well as readmission within 30 days. The outcomes were defined to be positive if it developed within 30 days of the surgical date as indicated by the primary team using ICD-9 coding or if indicated in the discharge summary documentation. Mortality was determined using electronic medical records that is linked to our national health registry. This registry includes information from all primary healthcare services and hospitals in Singapore. If the patient has deceased, this would be indicated on the record, including the date of death. Proof that a patient was alive was confirmed by searching for evidence of any subsequent healthcare visits, prescriptions, laboratory and radiological investigations within the time period. 
Table 1 Table showing the demographic, clinical and surgical data of the population studied

\begin{tabular}{|c|c|c|c|c|c|}
\hline Demographics & & Known DM $(\boldsymbol{n}=602)$ & Undiagnosed DM $(\boldsymbol{n}=155)$ & No DM $(\boldsymbol{n}=1349)$ & $\boldsymbol{p}$-value \\
\hline Male (\%) & & $324(53.8)$ & $91(58.7)$ & $712(52.8)$ & 0.37 \\
\hline Age, mean & & $64.9\left(S D^{b} 10.3\right)$ & 64.7 (SD 11.3) & 63.0 (SD 10.9) & $<0.001$ \\
\hline \multirow[t]{4}{*}{ Ethnicity } & Chinese $(n=1479)(\%)$ & $356(59.1)$ & $95(61.3)$ & $1028(76.2)$ & $<0.001$ \\
\hline & Malay $(n=402)(\%)$ & $148(24.6)$ & $41(26.5)$ & $213(15.8)$ & \\
\hline & Indian $(n=178)(\%)$ & $81(13.5)$ & $17(11.0)$ & $80(5.9)$ & \\
\hline & Others $(n=47)(\%)$ & $17(2.8)$ & $2(1.3)$ & $28(2.1)$ & \\
\hline BMI, mean & & 26.5 (SD 5.67) & $25.6(S D 6.2)$ & 24.9 (SD 5.1) & $<0.001$ \\
\hline \multirow[t]{3}{*}{ Type of Anaesthesia } & GA (\%) & $420(77.9)$ & $124(86.1)$ & $1153(90.0)$ & $<0.001$ \\
\hline & RA (\%) & $71(13.2)$ & $15(10.4)$ & $87(6.8)$ & \\
\hline & MAC (\%) & $48(8.9)$ & $5(3.5)$ & $41(3.2)$ & \\
\hline Emergency case (\%) & & $213(35.4)$ & $63(40.6)$ & $315(23.4)$ & $<0.001$ \\
\hline \multirow[t]{4}{*}{ ASA $^{\mathrm{a}}$ Score } & ASA $1(\%)$ & NA & $16(10.3)$ & $174(12.9)$ & $<0.001$ \\
\hline & ASA 2 (\%) & $253(42.0)$ & $45(29.0)$ & $655(48.6)$ & \\
\hline & ASA 3 (\%) & $321(53.3)$ & $71(45.8)$ & $445(33.0)$ & \\
\hline & ASA 4 (\%) & $44(7.3)$ & $23(14.8)$ & $74(5.5)$ & \\
\hline \multirow{3}{*}{$\begin{array}{l}\text { John Hopkins Surgical } \\
\text { Severity Criteria }\end{array}$} & $1(\%)$ & $258(43.3)$ & $45(30.0)$ & $382(28.6)$ & $<0.001$ \\
\hline & $2(\%)$ & $262(44.0)$ & $51(34.0)$ & $728(54.5)$ & \\
\hline & $3(\%)$ & 76 (12.8) & $54(36.0)$ & $225(16.9)$ & \\
\hline
\end{tabular}

${ }^{a} A S A$ American Society of Anesthesiologists classification

${ }^{\mathrm{b}} S \mathrm{~S}$ Standard deviation

By definition of ASA, diabetics are considered to be $\geq$ ASA 2

Patients were stratified into the following categories: known diabetes (as indicated on the anesthesia records), undiagnosed diabetes (based on a fasting blood glucose $\geq 126 \mathrm{mg} / \mathrm{dL}$ or $\mathrm{HbA} 1 \mathrm{c} \geq 6.5 \%$ in patients without a prior diagnosis of diabetes), or no diabetes (as indicated on the anesthesia records or those who had no records of fasting blood glucose or HbA1c) [14, 16]. Fasting blood glucose values were from samples drawn from patients kept nil per os for a minimum of $8 \mathrm{~h}$. These samples were taken just before their scheduled surgeries whereby they would be fasted for at least $8 \mathrm{~h}$ for solids and $2 \mathrm{~h}$ for plain water as per our institution's anesthesia requirements.

To find significant perioperative variables to account for the adverse outcomes, a univariate analysis was first performed. Categorical data were analyzed using the chi-squared test and continuous data were analyzed using the Kruskal Wallis test. Significant variables were identified as those having a $p$-value of $\leq$ 0.2 , which were then analysed using Firth multivariate logistic regression to calculate the adjusted odds ratio. Significant factors were identified as those having a pvalue of $<0.05$.

All statistical analyses were done using IBM SPSS version 25.0 (Armonk, NY, USA) and R version 3.4.4. This manuscript adheres to the applicable STROBE guidelines.

\section{Results}

Patient demographics and surgical characteristics are shown in Table 1. A total of 2106 patients were studied. The population consisted of $53.5 \%$ males. Seventy percent of patients were of Chinese ethnicity, $19.1 \%$ to Malay, $8.5 \%$ to Indians, which closely reflects ethnic distribution in Singapore [17]. Overall, the mean age of the surgical population was 63.7 with the mean age of known diabetics at 64.9, undiagnosed diabetics at 64.7 and non-diabetics at 63.0. The mean BMI of our surgical population was 25.4, while the mean BMI in known diabetics, undiagnosed diabetics and non-diabetics was $26.5,25.6$, and 24.9 respectively.

Thirty-six percent $(n=757)$ of the surgical population was diabetic, of which, $79 \%(n=602)$ were known diabetics. The prevalence of undiagnosed diabetes in the surgical population was $7.4 \% \quad(n=155)$. Among the undiagnosed diabetics, $88 \%$ had a fasting blood glucose of $>126 \mathrm{mg} / \mathrm{dL}$ and $78.5 \%$ had a HbA1c $>6.5$ (Fig. $1 \mathrm{a}$ and b). The mean and median HbA1c of known diabetics were 7.9 and $7.5 \%$, while the mean and median HbA1c for undiagnosed diabetics were 7.2 and $6.8 \%$ respectively (Fig. 2a and b). The mean random blood glucose was $153 \mathrm{mg} / \mathrm{dL}$ for the whole population $(n=1083)$, with $36.4 \%$ of known diabetics $(n=414)$ and $20.5 \%$ of unknown diabetics $(n=$ 112) having a random blood glucose $\geq 200 \mathrm{mg} / \mathrm{dL}$. 


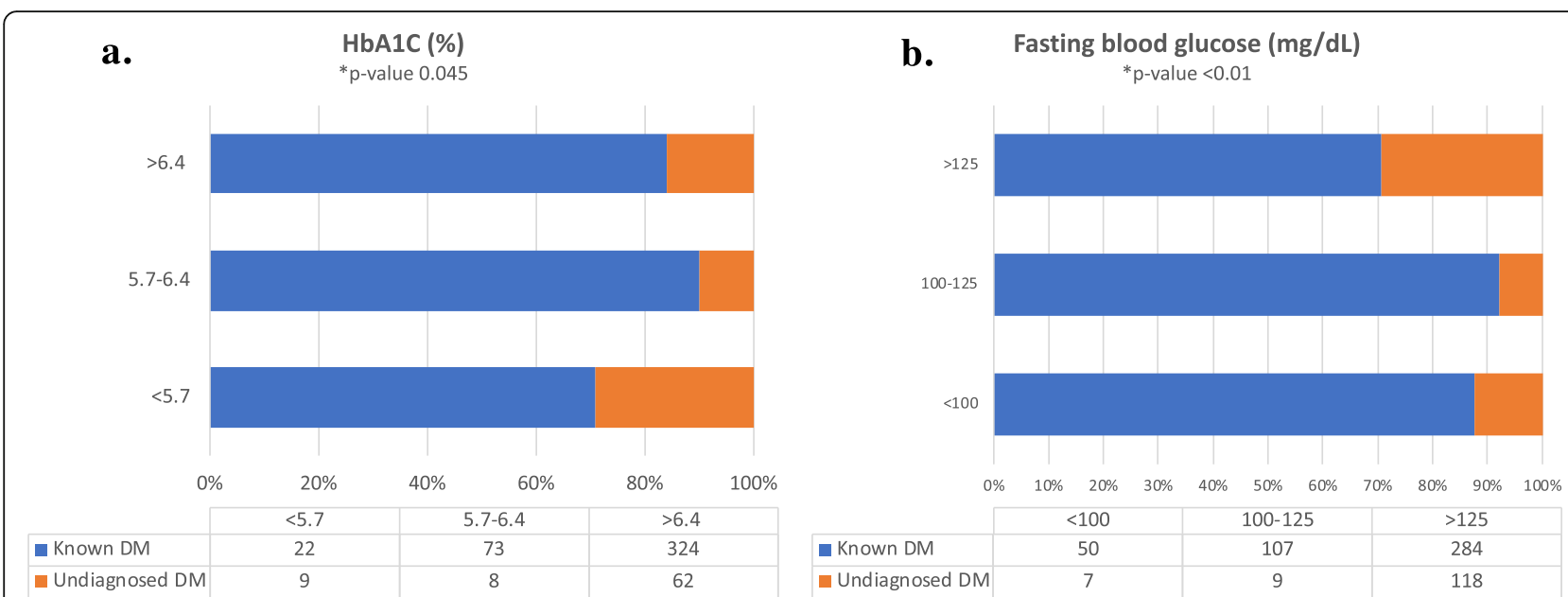

Fig. 1 a HbA1c levels amongst known and undiagnosed diabetics in the surgical population. b Fasting blood glucose levels amongst known and undiagnosed diabetics in the surgical population. DM - diabetes mellitus

The patient outcomes of known and undiagnosed diabetics compared with non-diabetics are shown in Table 2. Our results show that undiagnosed diabetics had a threefold increase in 1-year mortality compared to nondiabetics (adjusted OR $3.46(1.80-6.49) p<0.001)$. No statistically significant relationship was found between the known diabetics and one-year mortality. However, the known diabetics were at increased risk for morbidity in terms of increased risks of new onset atrial fibrillation (adjusted OR $2.48(1.01-6.25) p=0.047)$, infection (adjusted OR $1.49(1.07-2.07) p=0.017)$, readmission within 30 days (adjusted OR $1.62(1.17-2.25) p=0.004)$ and of note, 30day mortality (adjusted OR $3.11(1.16-8.56) p=0.025)$.

\section{Discussion}

Undiagnosed diabetes is a significant and worrying epidemic with a prevalence of $7.4 \%$ in our Asian surgical population. The mean $\mathrm{HbA} 1 \mathrm{c}$ and proportion of patients with random blood glucose $\geq 200 \mathrm{mg} / \mathrm{dL}$ are lower in the undiagnosed diabetics than the known diabetics, suggesting that undiagnosed diabetics have a biochemically less severe form of diabetes at the point of testing. Despite this, our results indicated that undiagnosed diabetics had a three-fold increase in 1-year mortality compared to non-diabetics - a mortality disadvantage that was not seen in known diabetics.

Even in the non-surgical population, patients with prediabetes have been associated with increased risk of morbidity and mortality as shown in a meta-analysis from 53 non-surgical studies [18]. A recent Korean cohort study of almost 500,000 non-surgical patients suggests that the risk could be amplified in the Asian population due to different adiposity distributions from the Westerners [19, 20]. Therefore, it can be postulated that if patients with prediabetes are already at risk, underdiagnosed diabetics with greater biochemical derangement undergoing the stress of surgery would be at an even higher risk.
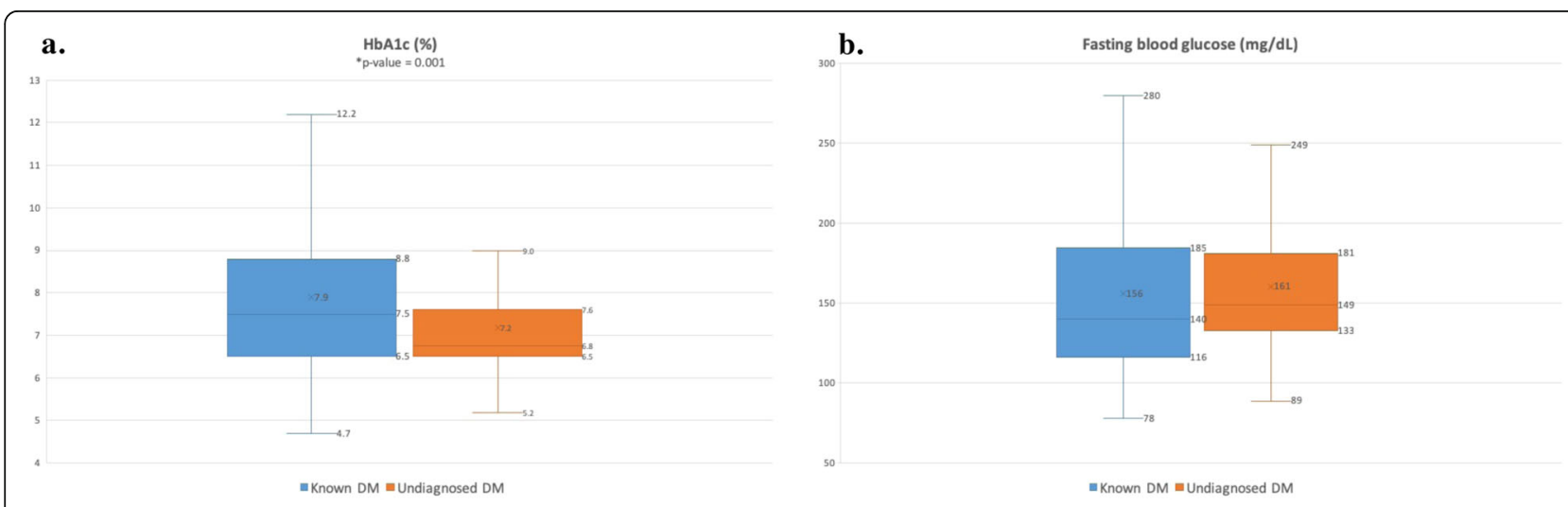

Fig. 2 a Box and whisker chart of mean and median HbA1c levels amongst known and undiagnosed diabetics. $\mathbf{b}$ Box and whisker chart of mean and median fasting blood glucose levels amongst known and undiagnosed diabetics. $x$ - mean value; DM - diabetes mellitus 
Table 2 Table showing the outcomes of undiagnosed diabetics and known diabetics compared to non-diabetics in both univariate and multivariate regression models

\begin{tabular}{|c|c|c|c|c|c|}
\hline & & Univariate analysis & & Multivariable analysis & \\
\hline & & Odds ratio (95\% Confidence interval) & $\boldsymbol{p}$-value & Adjusted odds ratio ( $95 \%$ Confidence interval) & $\boldsymbol{p}$-value \\
\hline 30-day readmissic & & & & & \\
\hline Undiagnosed $\mathrm{DM}^{\mathrm{c}}$ & $(n=12)$ & $0.98(0.50-1.78)$ & 0.955 & $0.80(0.42-1.54)$ & 0.503 \\
\hline Known DM & $(n=83)$ & $1.71(1.26-2.33)$ & $<0.001$ & $1.62(1.17-2.25)$ & 0.004 \\
\hline 30-day infection & & & & & \\
\hline Undiagnosed DM & $(n=25)$ & $2.2(1.33-3.53)$ & 0.0015 & $1.26(0.73-2.11)$ & 0.397 \\
\hline Known DM & $(n=89)$ & $1.73(1.28-2.33)$ & $<0.001$ & $1.49(1.07-2.07)$ & 0.017 \\
\hline 30-day mortality & & & & & \\
\hline Undiagnosed DM & $(n=3)$ & $3.50(0.86-11.2)$ & 0.076 & $2.15(0.51-7.38)$ & 0.273 \\
\hline Known DM & $(n=10)$ & $2.44(1.00-6.03)$ & 0.050 & $3.11(1.16-8.56)$ & 0.025 \\
\hline 1-year mortality & & & & & \\
\hline Undiagnosed DM & $(n=18)$ & $4.86(2.64-8.66)$ & $<0.001$ & $3.46(1.80-6.49)$ & $<0.001$ \\
\hline Known DM & $(n=23)$ & $1.25(0.74-2.09)$ & 0.400 & $1.17(0.66-2.02)$ & 0.587 \\
\hline New onset atrial $f$ & illation & & & & \\
\hline Undiagnosed DM & $(n=4)$ & $4.54(1.31-13.6)$ & 0.020 & $2.52(0.69-8.01)$ & 0.151 \\
\hline Known DM & $(n=12)$ & $2.91(1.25-7.00)$ & 0.013 & $2.48(1.01-6.25)$ & 0.047 \\
\hline
\end{tabular}

${ }^{C} D M$ Diabetes mellitus

The study highlights a second worrying trend of this silent killer; that known diabetics in our population are not well controlled in the perioperative setting. The mean HbA1c of the known diabetic group was $7.9 \%$, with more than $36.4 \%$ of the group having a random blood glucose $\geq 200 \mathrm{mg} / \mathrm{dL}$. This has significant postoperative consequences. Our study found that known diabetics had a 1.5 -fold and 2.5 -fold increase in risks of adverse outcomes including postoperative infection and new onset atrial fibrillation respectively, which likely explains the increased 30-day readmission and mortality rates. However, this did not lead to more deaths at 1 year, which could be attributed to effective disease surveillance, follow-up and treatment.

Our finding of infective complications with poor diabetic control concurs with a recent meta-analysis which revealed that diabetics undergoing elective total knee replacement surgeries had increased risks of deep infection amongst other complications [21, 22]. This is in line with biological research whereby immune dysfunction occurs in a hyperglycemic environment resulting in impaired neutrophil function, altered chemotaxis and phagocytic activity, as well as impaired wound healing due to delayed collagen synthesis [23].

The finding of increased incidence of atrial fibrillation in diabetic patients with poor glucose control is in accordance with other large population-based cohort studies [24-26]. Development of atrial fibrillation could be a consequence of systemic inflammation or autonomic stimulation perioperatively in a susceptible myocardium with other predisposing factors like electrolyte abnormalities. Diabetes is postulated to cause structural, electromechanical and autonomic remodeling of the heart which increases the propensity for atrial fibrillation [27, 28]. Massera et al., studying 80,000 subjects, reported a higher 30-day mortality in patients with new onset atrial fibrillation compared to those without [29].

The increased risks of infection and atrial fibrillation were not seen in the undiagnosed diabetics in our surgical population. This is likely because known diabetics in our study population generally have a more severe form of the disease than the undiagnosed diabetics at the point of biochemical testing. This is evident by the higher mean HbA1c (7.9\% in known diabetics vs $7.2 \%$ in undiagnosed diabetics). Closer follow-up and higher index of suspicion for complications among known diabetics could account for the higher pick-up rates of infection, arrhythmia and readmission in our study population. On the other hand, because undiagnosed diabetics remain untreated and are not actively followed up, complications could progress, resulting in a significantly higher one-year mortality rate. This finding is compelling and highlights the importance of screening and treatment for patients aged 45 years and above presenting for elective surgery, with benefits that extend beyond the perioperative period to their subsequent general state of health and wellbeing.

A successful preoperative diabetic screening program cited by the American Diabetic Association is a diabetic clinic nested within a preoperative clinic. In the 
intervention group, patients with $\mathrm{HbA} 1 \mathrm{c}$ of $>8 \%$ are identified and treated. This saw a preoperative reduction of a mean HbA1c from 9.5 to $<7 \%$, with no increase in hypoglycemia or complications [30]. We therefore advocate implementation of similar multidisciplinary clinics. Early referrals for urgent optimization of newly diagnosed and poorly controlled diabetes will minimize delay in surgery. While the UK NHS' 'Super Six' model of care is lauded for including antenatal diabetes and diabetic nephropathy into primary care support, we believe that a seventh specialist diabetes care area could extend to the perioperative setting [31]. It is clear that it is the role of the perioperative physician to take ownership and collaborate timely care planning amongst patients, primary and specialist care teams. In hospital, the same stringent diabetic protocol (i.e. close monitoring and optimization of blood sugar levels, usage of an insulin sliding scale, strict diet control, screening for complications) should be implemented on newly diabetic patients.

We acknowledge limitations with a retrospective cohort study that may have selected for sicker patients with a higher index of suspicion of hyperglycemia to be screened for diabetes. The robustness of follow-up and treatment of diabetes post-surgery could not be studied as well. Some of our surgical population had no fasting blood glucose or HbA1c done which likely underestimates the prevalence of undiagnosed diabetes. However, this would serve to emphasize the magnitude of the issues highlighted in our study. Moreover, as HbA1c and fasting blood glucose are not routine pre-operative investigations by most clinical guidelines, our results are likely to be a true reflection of world-wide perioperative practice and outcomes.

Further studies would be needed to establish risk factors specific to the Asian population that are associated with undiagnosed diabetes. This would have the advantage of streamlining the screening process. A subsequent step would then be the need to conduct formal cost effectiveness analysis or ascertain the magnitude of adverse outcome reduction and ensure that a screening program is financially viable when balanced against health expenditures due to projected complications.

\section{Conclusion}

Undiagnosed diabetes is a prevalent problem in our Asian surgical population. It is associated with a significantly increased risk of one-year mortality compared to non-diabetics. This mortality disadvantage is not seen with the known diabetics, despite being biochemically more severe compared to the unknown diabetics at the point of testing.

Overall, this may justify opportune diabetes screening for patients, especially non-compliant patients, aged 45 years old and above, presenting for elective surgery without additional healthcare visits, fasting, or venepunctures. This may allow medical intervention and lifestyle modification at an earlier stage of disease. With effective surveillance, follow-up and treatment, this may reduce the social and economic burden of untreated diabetes in the long term.

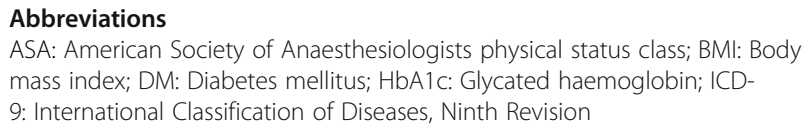

\section{Acknowledgments}

We would like to acknowledge Drs Irene Lim, Joanna Tan, Tan Shi Hui and Gong Xing Xing for their help in data collection.

\section{Authors' contributions}

WWT: This author contributed in the concept and design of the study, interpreting and analyzing the results and writing the manuscript. LKT: This author contributed in the concept and design of the study, interpreting and analyzing the results and writing the manuscript. LLL: This author contributed in the concept and design of the study, data collection and writing the manuscript. ES: This author contributed in analyzing the result and writing the manuscript. AP: This author contributed in data collection and writing the manuscript. WL: This author contributed statistical analysis of the results. JW: This author contributed in statistical analysis of the results. VC: This author contributed in statistical analysis of the results. LQL: This author contributed in the concept and design of the study, data collection, interpreting and analyzing the results and writing the manuscript. All authors read and approved the final manuscript.

\section{Funding}

No funding was received.

\section{Availability of data and materials}

All data generated or analysed during this study are included in this published article.

\section{Ethics approval and consent to participate}

Ethics committee approval from the Institutional Review Board (National Healthcare Group Domain Specific Review Board reference: 2016/01273).

Consent for publication

Not applicable.

\section{Competing interests}

The authors declare that they have no competing interests.

\section{Author details}

'Department of Anaesthesia, National University Health System, 5 Lower Kent Ridge Road, Singapore 119074, Singapore. ${ }^{2}$ Department of Anaesthesia, Khoo Teck Puat Hospital, 90 Yishun Central, Singapore 768828, Singapore.

Received: 31 March 2020 Accepted: 5 August 2020

Published online: 18 August 2020

\section{References}

1. Guariguata L, Whiting DR, Hambleton I, Beagley J, Linnenkamp U, Shaw JE. Global estimates of diabetes prevalence for 2013 and projections for 2035 Diabetes Res Clin Pract. 2014;103(2):137-49 [cited 2018 Nov 21] Available from: http://www.ncbi.nlm.nih.gov/pubmed/24630390.

2. Huang ES, Basu A, O'Grady M, Capretta JC. Projecting the future diabetes population size and related costs for the U.S. Diabetes Care. 2009;32(12): 2225-9 [cited 2018 Nov 21]. Available from: http://www.ncbi.nlm.nih.gov/ pubmed/19940225.

3. Vascular Events In Noncardiac Surgery Patients Cohort Evaluation (VISION) Study Investigators, Devereaux PJ, Chan MTV, Alonso-Coello P, Walsh M, Berwanger $\mathrm{O}$, et al. Association Between Postoperative Troponin Levels and 30-Day Mortality Among Patients Undergoing Noncardiac Surgery. JAMA. 
2012;307(21):2295 [cited 2018 Nov 21] Available from: http://www.ncbinlm. nih.gov/pubmed/22706835.

4. Meister KM, Hufford T, Tu C, Khorgami Z, Schauer PR, Brethauer SA, et al. Clinical significance of perioperative hyperglycemia in bariatric surgery: evidence for better perioperative glucose management. Surg Obes Relat Dis. 2018;14(11):1725-173 [cited 2018 Nov 21] Available from: http://www. ncbi.nlm.nih.gov/pubmed/30245036.

5. van den Boom W, Schroeder RA, Manning MW, Setji TL, Fiestan G-O, Dunson DB. Effect of A1C and Glucose on Postoperative Mortality in Noncardiac and Cardiac Surgeries. Diabetes Care. 2018;41(4):782-8 [cited 2018 Nov 21] Available from: http://www.ncbi.nlm.nih.gov/pubmed/2944 0113.

6. Kwon S, Thompson R, Dellinger P, Yanez D, Farrohki E, Flum D. Importance of Perioperative Glycemic Control in General Surgery. Ann Surg. 2013;257(1): 8-14 [cited 2018 Nov 21] Available from: http://www.ncbi.nlm.nih.gov/ pubmed/23235393.

7. Kotagal $M$, Symons RG, Hirsch IB, Umpierrez GE, Dellinger EP, Farrokhi ET, et al. Perioperative Hyperglycemia and Risk of Adverse Events Among Patients With and Without Diabetes. Ann Surg. 2015;261(1):97-103 [cited 2018 Nov 21] Available from: http://www.ncbi.nlm.nih.gov/pubmed/25133 932.

8. Ata A, Lee J, Bestle SL, Desemone J, Stain SC. Postoperative Hyperglycemia and Surgical Site Infection in General Surgery Patients. Arch Surg. 2010; 145(9):858 [cited 2018 Nov 21] Available from: http://www.ncbi.nlm.nih.gov/ pubmed/20855756.

9. Frisch A, Chandra P, Smiley D, Peng L, Rizzo M, Gatcliffe C, et al. Prevalence and Clinical Outcome of Hyperglycemia in the Perioperative Period in Noncardiac Surgery. Diabetes Care. 2010;33(8):1783-8 [cited 2018 Nov 21] Available from: http://www.ncbi.nlm.nih.gov/pubmed/20435798.

10. Abdelmalak B, Abdelmalak JB, Knittel J, Christiansen E, Mascha E, Zimmerman $\mathrm{R}$, et al. The prevalence of undiagnosed diabetes in noncardiac surgery patients, an observational study. Can J Anesth Can d'anesthésie. 2010;57(12):1058-64 [cited 2018 Nov 21]. Available from: http://www.ncbi.nlm.nih.gov/pubmed/20922587.

11. Senker W, Stefanits H, Gmeiner M, Trutschnig W, Radl C, Gruber A. The impact of Type 2 Diabetes on the peri- and postoperative outcomes of minimally invasive fusion techniques in the lumbar spine. J Neurosurg Sci. 2018; [cited 2018 Nov 21]; Available from: http://www.ncbi.nlm.nih.gov/ pubmed/30014687.

12. Dimic $A$, Markovic $M$, Vasic D, Dragas $M$, Zlatanovic $P$, Mitrovic $A$, et al. Impact of diabetes mellitus on early outcome of carotid endarterectomy. Vasa. 2018:1-9 [cited 2018 Nov 21]. Available from: http://www.ncbi.nlm.nih. gov/pubmed/30192204.

13. Liew LQ, Teo WW, Seet E, Lean LL, Paramasivan A, Tan J, et al. Factors predicting one-year post-surgical mortality amongst older Asian patients undergoing moderate to major non-cardiac surgery- A retrospective cohort study. BMC Surg. 2020;20(1):11 [cited 2020 Mar 30] Available from: https:// bmcsurg.biomedcentral.com/articles/10.1186/s12893-019-0654-x.

14. Hoang QN, Pisani MA, Inzucchi S, Hu B, Honiden S. The prevalence of undiagnosed diabetes mellitus and the association of baseline glycemic control on mortality in the intensive care unit: A prospective observational study. J Crit Care. 2014;29(6):1052-6 [cited 2018 Nov 25]. Available from: http://www.ncbi.nlm.nih.gov/pubmed/25092614.

15. Phan TP, Alkema L, Tai ES, Tan KHX, Yang Q, Lim W-Y, et al. Forecasting the burden of type 2 diabetes in Singapore using a demographic epidemiological model of Singapore. BMJ Open Diabetes Res Care. 2014; 2(1):e000012 [cited 2018 Nov 21] Available from: http://www.ncbi.nlm.nih. gov/pubmed/25452860.

16. Giraldez RR, Clare RM, Lopes RD, Dalby AJ, Prabhakaran D, Brogan GX, et al. Prevalence and clinical outcomes of undiagnosed diabetes mellitus and prediabetes among patients with high-risk non-ST-segment elevation acute coronary syndrome. Am Heart J. 2013;165(6):918-925.e2 [cited 2018 Nov 25] Available from: http://www.ncbi.nlm.nih.gov/pubmed/23708162.

17. Singapore Department of Statistics. Populatiuon Trends. 2017; Available from: http://www.singstat.gov.sg/tablebuilder.

18. Huang Y, Cai X, Mai W, Li M, Hu Y. Association between prediabetes and risk of cardiovascular disease and all cause mortality: systematic review and meta-analysis. BMJ. 2016;355:15953 [cited 2018 Nov 25] Available from: http://www.ncbi.nlm.nih.gov/pubmed/27881363.

19. Lawes CMM, Parag V, Bennett DA, Suh I, Lam TH, Whitlock G, et al. Blood glucose and risk of cardiovascular disease in the Asia Pacific region.
Diabetes Care. 2004;27(12):2836-42 [cited 2018 Nov 25] Available from: http://www.ncbi.nlm.nih.gov/pubmed/15562194.

20. Kim NH, Kwon TY, Yu S, Kim NH, Choi KM, Baik SH, et al. Increased Vascular Disease Mortality Risk in Prediabetic Korean Adults Is Mainly Attributable to Ischemic Stroke. Stroke. 2017;48(4):840-5 [cited 2018 Nov 25] Available from: http://www.ncbi.nlm.nih.gov/pubmed/28258257.

21. Yang Z, Liu H, Xie X, Tan Z, Qin T, Kang P. The influence of diabetes mellitus on the post-operative outcome of elective primary total knee replacement. Bone Joint J. 2014;96-B(12):1637-43 [cited 2018 Nov 21] Available from: http://www.ncbi.nlm.nih.gov/pubmed/25452366.

22. Bower WF, Jin L, Underwood MJ, Lee JF, Lee KF, Lam YH, et al. Overt diabetes mellitus adversely affects surgical outcomes of noncardiovascular patients. Surgery. 2010;147(5):670-5 [cited 2018 Nov 21] Available from: http://www.ncbi.nlm.nih.gov/pubmed/20045546.

23. Geerlings SE, Hoepelman Al. Immune dysfunction in patients with diabetes mellitus (DM). FEMS Immunol Med Microbiol. 1999;26(3-4):259-65 [cited 2018 Nov 21] Available from: http://www.ncbi.nlm.nih.gov/pubmed/105 75137.

24. Zhou Z, Hu D. An epidemiological study on the prevalence of atrial fibrillation in the Chinese population of mainland China. J Epidemiol. 2008; 18(5):209-16 [cited 2018 Nov 25] Available from: http://www.ncbi.n/m.nih. gov/pubmed/18776706.

25. Iguchi Y, Kimura K, Aoki J, Kobayashi K, Terasawa Y, Sakai K, et al. Prevalence of atrial fibrillation in community-dwelling Japanese aged 40 years or older in Japan: analysis of 41,436 non-employee residents in Kurashiki-city. Circ J. 2008:72(6):909-13 [cited 2018 Nov 25] Available from: http://www.ncbi.nlm. nih.gov/pubmed/18503215.

26. Benjamin EJ, Levy D, Vaziri SM, D'Agostino RB, Belanger AJ, Wolf PA. Independent risk factors for atrial fibrillation in a population-based cohort. The Framingham Heart Study. JAMA. 1994;271(11):840-4 [cited 2018 Nov 25] Available from: http://www.ncbi.nlm.nih.gov/pubmed/8114238.

27. Tadic M, Cuspidi C. Type 2 diabetes mellitus and atrial fibrillation: From mechanisms to clinical practice. Arch Cardiovasc Dis. 2015;108(4):269-76 Available from: http://www.ncbi.nlm.nih.gov/pubmed/25858534.

28. Joshi KK, Tiru M, Chin T, Fox MT, Stefan MS. Postoperative atrial fibrillation in patients undergoing non-cardiac non-thoracic surgery: A practical approach for the hospitalist. Hosp Pract. 2015;43(4):235-44 [cited 2018 Nov 21] Available from: http://www.ncbi.nlm.nih.gov/pubmed/26414594.

29. Massera D, Wang D, Vorchheimer DA, Negassa A, Garcia MJ. Increased risk of stroke and mortality following new-onset atrial fibrillation during hospitalization. Europace. 2016;19(6):euw110 [cited 2018 Nov 21] Available from: http://www.ncbi.nlm.nih.gov/pubmed/27207814.

30. Mendez CE, Wainaina N, Walker RJ, Montagne W, Livingston A, Slawski B, et al. Preoperative Diabetes Optimization Program. Clin Diabetes. 2018;36(1): 68-71 [cited 2018 Nov 25] Available from: http://clinical.diabetesjournals. org/lookup/doi/10.2337/cd17-0088.

31. Kar Partha. Model of care. 2011 [cited 2018 Nov 25]. Available from: https:// www.porthosp.nhs.uk/departments/Diabetes-and-Endocrinology/ Documents/SuperSixModelofCare.pdf.

\section{Publisher's Note}

Springer Nature remains neutral with regard to jurisdictional claims in published maps and institutional affiliations.

\section{Ready to submit your research? Choose BMC and benefit from:}

- fast, convenient online submission

- thorough peer review by experienced researchers in your field

- rapid publication on acceptance

- support for research data, including large and complex data types

- gold Open Access which fosters wider collaboration and increased citations

- maximum visibility for your research: over $100 \mathrm{M}$ website views per year

At BMC, research is always in progress.

Learn more biomedcentral.com/submissions 